\title{
The data collection process established for the German DRG system over the last six years with focus on data quality Mathias Rusert
}

\author{
Address: Auf dem Seidenberg 3, Siegburg, 53721, Germany \\ Email: Mathias Rusert - mathias.rusert@inek-drg.de
}

from 24th Patient Classification Systems International (PCSI) Working Conference

Lisbon, Portugal. 8-II October 2008

Published: 27 November 2008

BMC Health Services Research 2008, 8(SuppI I):AlI doi:I0.II86/I472-6963-8-SI-A I I

This abstract is available from: http://www.biomedcentral.com/I472-6963/8/SI/AII

(c) 2008 Rusert; licensee BioMed Central Ltd.

\section{Introduction}

A key aspect of developing a successful DRG system is the quality of the underlying data. In Germany, about 18 million patient data and four million detailed patient cost data are collected annually to obtain an accurate and upto-date basis. Though routines are established in the collection process, the process has been developed and refined over the years (2002 to 2007). This leads to a continuous upgrading of data validation. An overview of the process of data collection is given with focus on the following questions:

- What happens to data in order to analyse it successfully and apply the results in the further development of the GDRG system?

- How can improvement of data quality be achieved? How can it be measured?

- How are approximately 18 million cases collected every year (data flow)?

- Which results are published to guarantee transparency?

There is an obligation for nearly all German hospitals (about 1,800) to transfer patient data according to a certain law of hospital remuneration. In addition, detailed patient cost data and augmentative patient data are provided by nearly 270 hospitals that participate voluntarily in a partial census. The collection of hospital data in Ger- many runs annually through a standardised technical process including several quality checks.

The data collection process from hospital into the relational databases of the German DRG Institute (InEK) is described, and details about the communication process and data security are given.

\section{Methods}

The German DRG dataset is complex and voluminous. It covers nearly the complete range of German hospitalstructure data and case-related service data.

The dataset is described and some figures of the amount of data over the years are provided. The necessary technical equipment to control and carry out the processing is mentioned.

In order to ensure a high level of data quality, complex data validation procedures are installed. The complexity of data validation is described. The experience from the previous years is always integrated into the development of new and more differentiated checks. Communication with the participating hospitals plays a vital role for the continuous improvement of data quality, since they have the possibility of resending their data several times - after having studied validation reports.

An overview of the technical processes installed by InEK to carry out the procedural tasks is given. Proprietary soft- 
ware tools used to support the validation process are shown.

\section{Results}

After data collection and reassessment, the data is intensively used for further development of the G-DRG system (i.e., to calculate an accurate base rate or simulations). Deep insight data analyses to several aspects are carried out with the DRG data. In Germany, an obligation exists to publish the data to obtain transparency. An overview of the required publication is provided, and an example of a certain data browser (concerning the secondary research) is given.

\section{Conclusion}

1) Data quality is essential for a data-driven DRG system.

2) To achieve a high level of data quality:

a) intensive communication with the participating hospitals is needed;

b) experience from previous years should be integrated into the development of data validation.

3) Even with a large amount of high-quality data, there are still questions unanswered concerning the allocation of services to remuneration. Expert analyses beyond standard techniques are essential.

4) Publication of data, methods and results leads to transparency and acceptance.
Publish with Bio Med Central and every scientist can read your work free of charge

"BioMed Central will be the most significant development for disseminating the results of biomedical research in our lifetime. " Sir Paul Nurse, Cancer Research UK

Your research papers will be:

- available free of charge to the entire biomedical community

- peer reviewed and published immediately upon acceptance

- cited in PubMed and archived on PubMed Central

- yours - you keep the copyright

Submit your manuscript here:

http://www.biomedcentral.com/info/publishing_adv.asp 